\title{
May Distal Coronary Pressure Measurement taken from Anastomosed Radial Artery Grafts Predict Early-Term Graft Patency?
}

\section{Erkan Kuralay ${ }^{\star}$ and Abdullah Colak}

Cardiovascular Surgery Department, Lokman Hekim Hospital, Ankara, Turkey

*Corresponding author: Erkan Kuralay, ahmet taner kislali mahallesi deste-3 sitesi no 67 cayyolu-ankara, Turkey, Tel: 00905332309656 , E-mail: erkanece2000@yahoo.com

Received date: June 30, 2015; Accepted date: July 31, 2015; Published date: August 2, 2015

Copyright: ( 2015 Kuralay E. This is an open-access article distributed under the terms of the Creative Commons Attribution License, which permits unrestricted use, distribution, and reproduction in any medium, provided the original author and source are credited.

\begin{abstract}
Background: Visual estimates on angiography are inaccurate in assessing the functional significance of a coronary stenosis. Severity of stenosis in the native coronary artery is critical to both the short and long-term patency of the radial artery.

Materials and Methods: A one hundred patients were selected. Radial artery is used for all patients. After all distal anastomoses are done and the systolic blood pressure reached over $100 \mathrm{mmHg}$, we have made arterial pressure measurement from the proximal side of radial artery graft.

Results: All patients were followed-up. Serial postoperative coronary angiographies were performed at the first six postoperative months. There was no death in the first postoperative six months follow-up. We have detected ten radial artery graft occlusions and string sign. Five right coronary artery, four circumflex artery and one diagonal artery radial artery grafts occluded. The percentage of systolic aortic and coronary pressure measurement (C/Ao-s $\%$ ) on occluded graft patients was ranged from 81 to 97 . Percentage of diastolic aortic and coronary pressure measurement (C/Ao-d\%) was ranged from 83 to 90 . Percentage of mean aortic and coronary pressure measurement (C/Ao-m\%) was ranged from 84 to 95 .
\end{abstract}

Conclusion: We concluded that we can predict of radial artery prognosis based on the severity degree of coronary artery stenosis. We have found ten radial artery grafts occluded. Unfortunately ten radial artery measurements are not enough for establishing a reliable cut-off value. We need more studies for creating a cut-off value determination.

Keywords: Angiography; Artery grafts; Radial artery

\section{Introduction}

Prone to spasm of radial artery (RA) was the primary concern for the use of arterial conduit for myocardial revascularization. Spasm of RA was overcomed by calcium channel blockers and radial artery popularized in cardiac surgery. RA is being used as a second arterial conduit in world widely [1]. Severity of stenosis in the native coronary artery is critical to both the short and long-term patency of the RA because of the potentially negative effects of competitive flow when the stenosis is below $70 \%[2,3]$. Visual estimates of the severity of coronary stenosis are frequently very inaccurate. Angiography is sometimes inaccurate in assessing the functional significance of a coronary stenosis. For this reason Fractional Flow Reserve (FFR) is being used for accurately assessing functional significance of a coronary stenosis [4]. But currently, only $6 \%$ of patients had FFR measurement before revascularization procedure is carried out [5]. Most surgeons are using RA for revascularization without having enough information about the functional significance of coronary stenosis. These RA conduits may be occluded in a low degree coronary stenosis. Therefore we have preferentially performed a prospective study by using distal coronary artery pressure and aortic pressure measurements and try to predict short-term patency of the RA.

\section{Materials and Methods}

This study included 100 patients who received radial artery graft during beating heart surgery between the years of 2010 and 2014 years. Redo coronary surgery, patients with positive Allen test for radial artery, hemodynamically compromised patients during off-pump surgery are excluded from our study. Patients with previous myocardial infarction were also excluded because of changed myocardial resistance which cannot be controlled because of not using adenosine administration. Radial artery grafts were anastomosed to highest stenosed and good distal runoff coronary arteries to eliminate early graft occlusion causes and avoid confounding results. Ethical committee approval has been taken (2009/13445). Informed consent are obtained from all patients both distal pressure measurements and six months after control angiography. There were 37 female and 63 male patients. Thirty-one of patients have diabetes mellitus. Chronic obstructive pulmonary disease (COPD) found in 28 patients. Average left ventricle ejection fraction (EF) was $51 \%$.

To calculate the degree of coronary stenosis, the normal segment of the artery proximal to the lesion was used as a reference and the difference with the minimum luminal diameter of the stenotic lesion was considered the percent of stenosis. In the evaluation of the postoperative angiogram, Patent was defined as the status of the grafted coronary artery filled with angiographic contrast from the conduit without any irregularity (Figure 1B). String sign was a 
diffusely narrowed conduit filled with contrast but not seen to opacify the native coronary artery (Figure 1D). When a conduit did not fill with contrast at all, it was considered occluded and was included with string sign for the purposes of this analysis. Both of these latter findings were considered together and referred to as occlusion in the analysis [6]. Figure 1A shows critically stenosed obtuse marginal coronary artery, (Figure 1C) shows non-critical coronary artery stenosis.

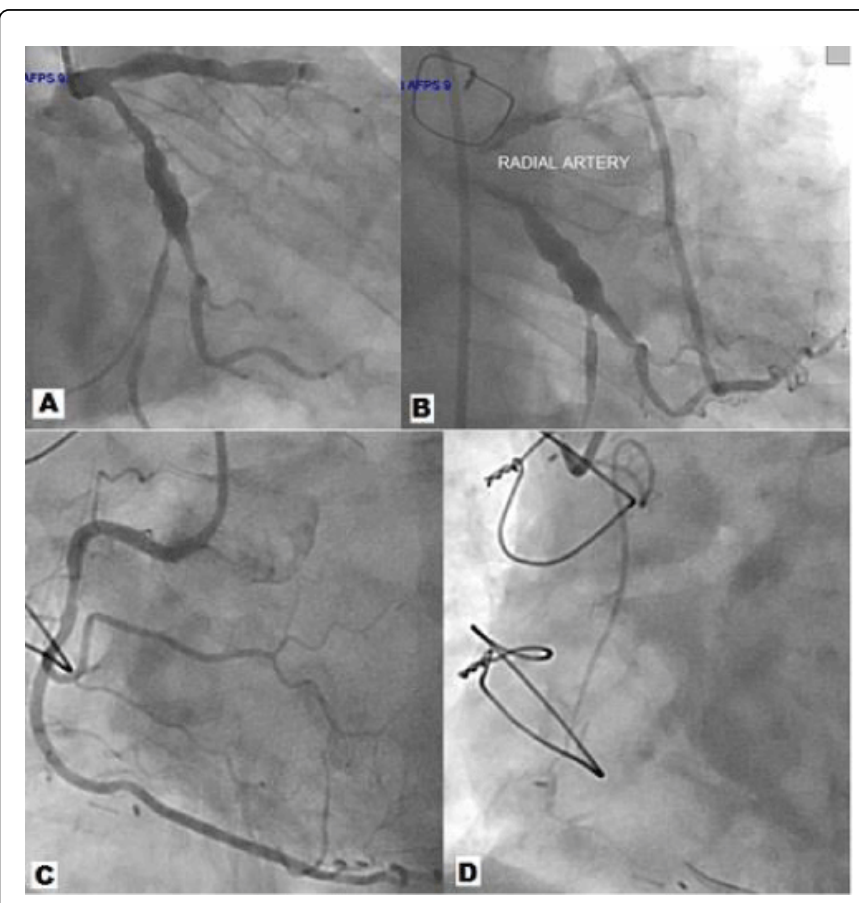

Figure 1: A) Preoperative angiogram of highly stenosed (90\%) obtuse marginal artery; B) Postoperative angiogram of patent radial artery (measurements $\mathrm{C} / \mathrm{Ao}-\mathrm{s} \%=32, \mathrm{C} / \mathrm{Ao}-\mathrm{d} \%=46, \mathrm{C} / \mathrm{Ao}-\mathrm{m} \%=61$ ); C) Postoperative angiogram of mildly stenosed (70\%) right coronary artery; D) Postoperative angiogram of string sign radial artery (measurements $\mathrm{C} / \mathrm{Ao}-\mathrm{s} \%=93, \mathrm{C} / \mathrm{Ao}-\mathrm{d} \%=92, \mathrm{C} / \mathrm{Ao}-\mathrm{m} \%=88$ ).

\section{Surgical Technique}

We have performed beating off-pump surgery to all patients. Left internal thoracic artery (LITA) and is routinely used for 94 patients. Left radial artery (RA) is also routinely used. Harvested radial artery grafts rinsed with warm saline/diltiazem/nitroglyserine/heparin solution to avoid early postoperative radial artery spasm. Calcium channel blockers are routinely used for prevent postoperative radial artery spasm. Saphenous vein graft was used for additional coronary surgery. Patient characteristics were summarized in (Table 1). Heparinization was done just after LITA harvested. Pericardium is opened and stay sutures are placed. Firstly left side coronary vessels are anastomosed on beating off-pump surgery. Then left anterior descending (LAD) artery and right coronary system are bypassed. Radial artery graft is used for highly stenosed and large coronary artery. RA is used for LAD territory in six patients. After all distal anastomoses are done heart placed to pericardial cradle and waited for recovery of hemodynamic condition. During this time we have tried not to use inotropic agents. Warm saline solutions $\left(>30^{\circ} \mathrm{C}\right)$ spilled over the heart into the pericardial cradle. When the systolic blood pressure reaches over $100 \mathrm{mmHg}$ we have made arterial pressure measurement from the proximal side of RA graft by using small vascular cannula tied to proximal end of the RA and attached to manometer line. Both radial artery and aortic pressures were recorded instantaneously. We have temporarily placed bulldog clamp to LITA graft to avoid collateral blood supplying effect during the pressure measurement. Systemic arterial pressure measurements are done from ascending aorta. Both ascending aorta and radial artery distal pressure were simultaneously recorded. Systolic, diastolic and mean artery pressures are routinely recorded. Pressure differences are calculated. Bulldog clamp on LITA released just after measurements. All proximal anastomoses were done to the ascending aorta.

\begin{tabular}{|c|c|c|c|}
\hline & $\begin{array}{lr}\begin{array}{l}\text { Patent } \\
\text { Artery } \\
(n o=90)\end{array} & \text { Radial } \\
& \end{array}$ & $\begin{array}{l}\text { Occluded/String } \\
\text { sign Radial Artery } \\
\text { Graft (no=10) }\end{array}$ & $P$ value \\
\hline Age & $66.2 \pm 9$ & $60.4 \pm 12$ & 0.71 \\
\hline Sex / male & 53 & 6 & 0.93 \\
\hline Diabetes mellutus & 37 & 4 & 0.56 \\
\hline Hypertension & 61 & 4 & 0.18 \\
\hline $\begin{array}{l}\text { Average preoperative } \\
\text { ejection fraction }(\%)\end{array}$ & $51 \pm 4.5$ & $55 \pm 3.2$ & 0.23 \\
\hline $\begin{array}{l}\text { Number of distal } \\
\text { anastomosis }\end{array}$ & 2.3 & 2.6 & 0.23 \\
\hline $\begin{array}{l}\text { Peripheric vascular } \\
\text { disease }\end{array}$ & 11 & 2 & 0,31 \\
\hline
\end{tabular}

Table 1: Patient characteristics.

\section{Results}

All patients were followed-up. Serial postoperative coronary angiographies were performed at first six postoperative months. There was not death within the first postoperative six months follow-up. We have detected ten radial artery graft occlusions and string sign. (Table 2) summarizes patient characteristics and measurements accordingly. Five right coronary artery, four circumflex artery and one diagonal artery radial artery grafts occluded. Six male and four female patients has occluded radial artery grafts. Percentage of systolic coronary and aortic pressure measurement (C/Ao-s\%) on occluded graft patients was ranged from 81 to 97 . Percentage of diastolic coronary and aortic pressure measurement (C/Ao-d\%) was ranged from 83 to 90. Percentage of the mean coronary and aortic pressure measurement (C/Ao-m\%) was ranged from 84 to 95 . Ninety radial artery grafts were patent. Graft distribution to coronary arteries as follows; 27 to right coronary artery, 35 to circumflex system, 6 to LAD artery, 8 to diagonal artery, 14 to right posterior descending artery were done. Average C/Ao-s\% of patent radial artery graft was between 29 and 67, average $\mathrm{C} / \mathrm{Ao}-\mathrm{d} \%$ of patent radial artery graft was between 21 and 70 , average $\mathrm{C} / \mathrm{Ao}-\mathrm{m} \%$ of patent radial artery graft was between 30 to 74 . 
Page 3 of 4

\begin{tabular}{|c|c|c|c|c|c|c|c|}
\hline Age & $M / F$ & Vessel & Stenosis (\%) & C/Ao-s\% & C/Ao-d\% & C/Ao-m\% & Status \\
\hline 52 & $\mathrm{~F}$ & D1 & 75 & 85 & 90 & 86 & OCCLUDED \\
\hline 71 & M & OM & 80 & 97 & 92 & 95 & STRING SIGN \\
\hline 44 & M & RCA & 70 & 93 & 92 & 88 & STRING SIGN \\
\hline 66 & M & R-PDA & 80 & 92 & 85 & 87 & OCCLUDED \\
\hline 67 & M & CxPL & 75 & 97 & 89 & 95 & STRING SIGN \\
\hline 72 & M & $\mathrm{OM}$ & 85 & 91 & 90 & 89 & STRING SIGN \\
\hline 68 & $\mathrm{~F}$ & RCA & 85 & 85 & 87 & 90 & OCCLUDED \\
\hline 58 & $\mathrm{~F}$ & R-PDA & 75 & 85 & 83 & 85 & OCCLUDED \\
\hline 45 & M & RCA & 80 & 88 & 90 & 87 & STRING SIGN \\
\hline 61 & $\mathrm{~F}$ & $\mathrm{OM}$ & 80 & 81 & 85 & 84 & STRING SIGN \\
\hline
\end{tabular}

Table 2: Measurements summary.

\section{Discussion}

Radial artery is the second most common arterial graft in coronary surgery. Mostly radial artery is used to relatively large and severely stenotic coronary arteries. Long term patency of radial artery in low grade stenosis is extremely poor [1-3]. We have quantitatively approached to radial artery graft by using distal coronary pressure measurement not to determine degree of cornary stenosis but also predict early-term radial artery graft patency.

Severity of stenosis in the native coronary artery is critical to both the short- and long-term patency of the RA, because of the potentially negative effects of competitive flow when the stenosis is below $70-80 \%$ [2-7]. Coronary angiography is limited in its ability to determine the physiologic significance of coronary stenosis. Especially in patients with intermediate stenosis, angiographic information does not correlate well with the functional significance of a lesion. This uncertainty may result in unnecessary revascularization of insignificant lesions or failure to revascularize the clinically significant ones. It is also well recognized that angiographic grading of lesion severity is at best an imperfect predictor of the physiological significance (i.e., flow-limiting status) of coronary lesions. Technical features related to patient morphology or vessel tortuousity can also limit visualization of specific coronary narrowings [8-10]. There are conflicting results on accuracy of coronary angiography even in left main coronary artery (LMCA) lesions. Isner has demonstrated that degree of narrowing LMCA is underestimated or overestimated in $71 \%$ of patients [11]. Accurately determination of coronary narrowing in quantitative coronary angiography is also changed by used catheter diameters. Ellis has demonstrated that 6 French catheters may not be as accurate in the determination of absolute artery dimension as 8 French catheters [12]. Furthermore it needs to be recognized that visual estimates of the severity of coronary stenosis are frequently very inaccurate when compared to more objective measurements such as fractional flow reserve (FFR). FFR can be derived easily from the ratio of the mean distal coronary-artery pressure to the aortic pressure during maximal vasodilatation. This index is independent of changes in systemic blood pressure and heart rate and unaffected by conditions known to increase base-line myocardial flow [8-13]. But hyperemia is required to achieve the necessary resistance conditions and this is provided by adenosine administration. Most cardiologists avoiding use of adenosine and Sen et al. present a novel concept, the instantaneous wave-free pressure ratio (iFR), using and expanding on the tenets of FFR [14]. iFR, an index of stenosis severity, is based on the instantaneous ratio of translesional pressures acquired during a specific period of diastole in which the coronary microcirculatory resistance is constant and minimal, fulfilling the FFR resistance criteria without the need for adenosine hyperemia. iFR is basically translesional ratio of diastolic pressures. The first multicenter study, ADVISE (Adenosine Vasodilator Independent Stenosis Evaluation), compared iFR to FFR in 157 intermediate lesions and found the diagnostic accuracy of iFR to be $90 \%$, with an optimal iFR cut-off of 0.90 [12]. We have made a kind of iFR study in operating room. iFR studies have used instantaneous ratio of translesional pressures in specific diastole period. We have measured systolic, diastolic, mean artery pressures after distal radial artery anastomosis is completed. We have made comparison distal coronary pressure which is measured from radial artery that anastomosed coronary artery and aorta pressure which is obtained from ascending aorta cannula. We think that we can predict of radial artery prognosis based on severity of coronary artery stenosis. We have found ten radial artery grafts occluded. But patients are completely asymptomatic because of functionally insignificant lesions despite these lesions are considered visually significant on coronary angiogram. Lowest $\mathrm{C} / \mathrm{Ao}-\mathrm{s} \%$ on occluded graft patients was 81 and lowest C/Ao-d\% was 83 and lowest $\mathrm{C} / \mathrm{Ao}-\mathrm{m} \%$ was 84 . Unfortunately ten radial artery measurements are not enough for establish a cut-off value. If we would establish a cut-off value, surgeons can remove radial artery graft and use for another coronary artery to avoid early graft occlusion. We need more studies for creating a cut-off value determination. Unfortunately there is not any data about distal coronary pressure measurement in literature. So we cannot compare our results with other studies. If we accurately elaborated a cut-off value then we can change radial artery grafts to other coronary vessels. 
Citation: Kuralay E, Colak A (2015) May Distal Coronary Pressure Measurement taken from Anastomosed Radial Artery Grafts Predict EarlyTerm Graft Patency?. J Cardiovasc Dis Diagn 3: 216. doi:10.4172/2329-9517.1000216

Page 4 of 4

\section{References}

1. Buxton BF, Raman JS, Ruengsakulrach P (2003) Radial artery patency and clinical outcomes: five-year interim results of a randomized trial. J Thorac Cardiovasc Surg 125: 1363-1371.

2. Desai ND, Naylor CD, Kiss A (2007) Impact of patient and target-vessel characteristics on arterial and venous bypass graft patency: insight from a randomized trial. Circulation 115: 684-691.

3. Tatoulis J (2013) Total arterial coronary revascularisation-patient selection, stenosis, conduits, targets. Ann Cardiothorac Surg 2: 499-506.

4. Tonino PAL, Fearon WF, De Bruyne B, Oldroyd KG, Leesar MA, et al. (2010) Angiographic Versus Functional Severity of Coronary Artery stenosis in the FAME Study Fractional Flow Reserve Versus Angiography in Multi vessel Evaluation. J Am Coll Cardiol 55: 2816-2821

5. 2011 Procedural Reimbursement Guide. Dec 2010. Available at: http :// www.bostonscientific.com/templatedata/imports/collateral/ Reimbursement/ Interventional Cardiology 2011/90642893-2011 PRG Final Updated PFS.pdf. Accessed May 2, 2011.

6. Yie K, Na CY, Oh SS, Kim JH, Shinn SH, et al. (2008) Angiographic results of the radial artery graft patency according to the degree of native coronary stenosis. Eur J Cardio-thoracic Surg 33: 341-348

7. Cao C, Manganas C, Horton M (2013) Angiographic outcomes of radial artery versus saphenous vein in coronary artery bypass graft surgery: A meta-analysis of randomized controlled trials. J Thorac Cardiovasc Surg 146: $255-261$.

8. Pijls NHJ, Bruyne BD, Peels K, Van Der Voort PH, Bonnier HJRM, et al. (1996)Measurement of fractional flow reserve to assess the functional severity of coronary-artery stenosis N Engl J Med 334: 1703-1708.
9. Pijls NHJ, van Son JAM, Kirkeeide RL, De Bruyne B, Gould KL (1993) Experimental basis of determining maximum coronary, myocardial, and collateral blood flow by pressure measurements for assessing functional stenosis severity before and after percutaneous transluminal coronary angioplasty. Circulation 87: 1354-1367.

10. De Bruyne B, Baudhuin T, Melin JA (1994) Coronary flow reserve calculated from pressure measurements in humans: validation with positron emission tomography. Circulation 89: 1013-1022.

11. Isner JM, Kisner J,Kent KM, Ronan JA, Ross A (1981) Accuracy of angiographic determination of left main coronary arterial narrowing. Angiographic-Histologic correlative analysis in 28 patients. Circulation 63: 1056-1064

12. Ellis SG, Pinto IMF, McGillem MJ, DeBoe SF, LeFree MT, et al. (1991) Accuracy and reproducibility of Quantitative coronary angipgraphy using 6 and 8 French catheters with cineangipgraphic acquisition. Catheterization and Cardiovascular Diagnosis 22: 52-55.

13. De Bruyne B, Paulus WJ, Pijls NHJ (1994) Rationale and application of coronary transstenotic pressure gradient measurements. Cathet Cardiovasc Diagn 33: 250-261.

14. Sen S, Escaned J, Malik IS (2012) Development and validation of a new adenosine-independent index of stenosis severity from coronary waveintensity analysis: results of the ADVISE (ADenosine Vasodilator Independent Stenosis Evaluation) study. J Am Coll Cardiol 59: 13921402 . 